\title{
Effects of small-dose remifentanil combined with index of consciousness monitoring on gastroscopic polypectomy: a prospective, randomized, single-blinded trial
}

\author{
Minqiang Liu', Hongyan $\mathrm{Wu}^{2}$, Danling Yang ${ }^{2}$, Fengxian $\mathrm{Li}^{3}$, Zhichao $\mathrm{Li}^{1}$, Song Wang ${ }^{1}$ and Renliang $\mathrm{He}^{1 *}$ (D)
}

\begin{abstract}
Background: With the development of painless diagnosis and treatment, remifentanil, a synthetic opioid agonist, is increasingly used in gastroscopy for its rapid, short-term, and potent analgesic effect. However, the dosage of remifentanil used in endoscopy is unclear. Index of consciousness (IOC) is a new anesthesia depth-monitoring indicator that can be divided into index of consciousness $1\left(\mid \mathrm{IOC}_{1}\right)$ and index of consciousness $\left.2(\mid \mathrm{OOC})_{2}\right) ; O C_{1}$ is used for estimating a patient's sedation state, whereas $I O C_{2}$ reflects analgesic depth. We hypothesized that combining with $I O C_{1}$ and $I O C_{2}$ monitoring may be helpful to identify an optimal remifentanil dosage in gastroscopic polypectomy.

Methods: One hundred twenty patients scheduled for gastroscopic polypectomy were enrolled and were randomly assigned to remifentanil $2 \mathrm{ng} / \mathrm{mL}$ (group R2), $4 \mathrm{ng} / \mathrm{mL}$ (group R4), or $6 \mathrm{ng} / \mathrm{mL}$ (group R6), and 40 cases were in each group. During the anesthesia period, remifentanil was kept at the initial given concentration but propofol was adjusted according to $I O C_{1}$. The primary outcomes were the dosage of propofol and remifentanil. The secondary outcomes were the variety of $I O C_{1}$ and $I O C_{2}$, patients' awakening time, and peri-operative adverse reactions such as hypotension, hypertension, bradycardia, tachycardia, body movements, hypoxemia, therapy interruption, nausea, vomiting, aspiration, and intra-operative awareness.

Results: With the increasing dosage of remifentanil, the propofol dosage and patients' awakening time decreased significantly, the morbidity of hypertension and body movements also declined, but the incidence of hypotension, bradycardia, and hypoxemia rose. In group R2, the value of $\mathrm{IOC}_{2}$ remained above 50 during the treatment. However, $\mathrm{IOC}_{2}$ dropped to below 30 at the beginning of the gastroscopy in group $\mathrm{R} 6$, and there was statistical difference in hypoxemia between groups R2 and R6 $(P<0.05)$.
\end{abstract}

Conclusions: With the help of $\mathrm{IOC}$ monitoring, we found that a target concentration of remifentanil $4 \mathrm{ng} / \mathrm{mL}$ is comparatively ideal in patients under gastroscopic polypectomy.

Trial registration: Chinese Clinical Trial Register: ChiCTR-OOD-16009489, on October 19, 2016.

Keywords: Remifentanil, Index of consciousness, Gastroscopy, Polypectomy

\footnotetext{
* Correspondence: szherenliang@163.com

${ }^{1}$ Department of Anesthesiology, Shenzhen Third People's Hospital, No. 29

Bulan Road, Longgang District, Shenzhen 518112, Guangdong, China

Full list of author information is available at the end of the article
}

(c) The Author(s). 2018 Open Access This article is distributed under the terms of the Creative Commons Attribution 4.0 International License (http://creativecommons.org/licenses/by/4.0/), which permits unrestricted use, distribution, and reproduction in any medium, provided you give appropriate credit to the original author(s) and the source, provide a link to the Creative Commons license, and indicate if changes were made. The Creative Commons Public Domain Dedication waiver (http://creativecommons.org/publicdomain/zero/1.0/) applies to the data made available in this article, unless otherwise stated. 


\section{Background}

Gastric polyp is the bulging of the gastric mucosa, usually occurring in the gastric antrum [1]. The patient may have upper abdominal pain, abdominal distension, dysphagia, or loss of appetite or may have no discomfort; nowadays, the major diagnostic method is gastroscopy [2]. Because the most common histologic type of gastric polyp is the hyperplastic polyp, which has certain risks of turning into a malignant tumor [3], the main therapy for this disease is gastroscopic polypectomy [1, 4]. However, endoscopic therapy is usually associated with certain adverse reactions such as nervousness, nausea, vomiting, and choking cough $[5,6]$, and severe discomfort such as coughing or body movements may lead to aggravation of a pre-existing condition or even interruption of treatment, especially in some critical patients with physiological dysfunction (for instance, respiratory disease or cardiovascular disease) [7]. Therefore, finding a suitable way to enhance patient compliance is very important.

It has been reported that the administration of intravenous anesthesia can effectively inhibit upper airway reflex, eliminate patients' anxiety, and improve patients' comfort during endoscopy, which led to an increase of patients' willingness to undergo follow-up gastroscopic examination or treatment $[8,9]$. In previous studies, a number of reports have confirmed the efficacy of general anesthesia in gastrointestinal endoscopy [10-12], and remifentanil proved to be a safe and effective opioid receptor agonist during endoscopy because of its effective inhibition of autonomic nervous reflex in the upper respiratory tract and rare adverse effects on the cardiovascular and respiratory systems [13-15]. However, few reports explore the optimal dose of remifentanil during gastroscopic treatment. With the development of anesthesiology, intra-operative anesthesia depth monitoring is increasingly being used in the clinic. Index of consciousness (IOC) is a new indicator that can effectively measure patients' sedation depth and analgesic state [16]. IOC can be divided into index of consciousness $1\left(\mathrm{IOC}_{1}\right)$ and index of consciousness 2 $\left(\mathrm{IOC}_{2}\right) ; \mathrm{IOC}_{1}$ is used for estimating a patient's sedation state, whereas $\mathrm{IOC}_{2}$ reflects analgesic depth [17]. Previous studies have shown that accurate anesthesia depth monitoring can help optimize the use of anesthetics, shorten the recovery time, and reduce post-operative analgesia complications [18, 19]. In this research, we combined both $\mathrm{IOC}_{1}$ and $\mathrm{IOC}_{2}$ monitoring, as the validity of $\mathrm{IOC}_{1}$ in the evaluation of sedation depth has been confirmed, we hypothesized that $\mathrm{IOC}_{2}$ monitoring may help in determining an appropriate dosage of remifentanil in gastroscopic polypectomy.

\section{Methods}

\section{Study design and setting}

This study was a prospective, randomized, single-blind trial. It was conducted with the approval of the medical ethics committee of Shenzhen Third People's Hospital (No. 29 Bulan Road, Longgang District, Shenzhen, Guangdong, China, approval number 2016-001; October 17, 2016) and was registered in the Chinese Clinical Trial Register (http://www.chictr.org.cn/index.aspx, registration number ChiCTR-OOD-16009489; October 19, 2016). Patients of American Society of Anesthesiologists (ASA) class I or II, undergoing selective gastroscopic polypectomy, were recruited. Written informed consent was obtained and documented for all participants before anesthesia. The exclusion criteria were those older than 60 years or younger than 18 years, pregnancy, body weight exceeding $20 \%$ of the ideal body weight, active upper gastrointestinal bleeding, a history of bronchial asthma or chronic obstructive pulmonary disease, upper airway infection in the previous 2 weeks, impaired kidney or liver functions, drug abuse, a known hypersensitivity to propofol or remifentanil, and patients who were expected to have difficult airway intubation or an expected operation time exceeding $30 \mathrm{~min}$. Furthermore, participants would be excluded after recruitment if the anesthesia protocol or endoscopic therapy was temporarily changed for any reason. The structure of the study is illustrated in Fig. 1.

\section{Anesthesia}

All patients fasted for $10 \mathrm{~h}$ but received $10 \mathrm{~mL}$ of oral dyclonine (dyclonine hydrochloride mucilage, batch number 17011021, Yangtze River Pharmaceutical Co., Ltd., Handan, China) $15 \mathrm{~min}$ prior to entering the gastroscopy room. After the patient's admission, $\mathrm{IOC}_{1}$ and $\mathrm{IOC}_{2}$ were monitored continuously. Electrocardiogram (ECG), non-invasive blood pressure (NIBP), and pulse oxygen saturation $\left(\mathrm{SpO}_{2}\right)$ were constantly monitored by using the GE Datex-Ohmeda $\mathrm{S} / 5^{\mathrm{mm}}$ anesthesia work station (ADU, Datex-Ohmeda Inc., Madison, WI, USA). Peripheral venous access was secured by using a 24-G intravenous needle on the right dorsal hand, a left-side position was taken, and normal saline was infused at a rate of $10 \mathrm{~mL} \cdot \mathrm{kg}^{-1} \cdot \mathrm{h}^{-1}$. All anesthetics were administered via a target-controlled infusion system (Fresenius Kabi Base Primea, Fresenius Kabi Pharmaceutical Co. Ltd., Bad Homburg, Germany). Propofol (Propofol Medium and Long Chain Fat Emulsion Injection, batch number 16K15866, Fresenius Kabi Austria GmbH, Graz, Austria) was administered at an effect-site concentration of about 2 to $6 \mu \mathrm{g} / \mathrm{mL}$ (Marsh model) $10 \mathrm{~min}$ after the patient's admission. When $\mathrm{IOC}_{1}$ was stably maintained at about 40 to 60 for at least $1 \mathrm{~min}$, remifentanil (remifentanil hydrochloride for injection, batch number 6161009, Yichang Humanwell Pharmaceutical, Hubei, China) was infused with a plasma concentration of 2, 4, and $6 \mathrm{ng} / \mathrm{mL}$ (Minto model) in groups R2, R4, and R6, respectively. Gastroscopy was carried out after remifentanil reached 


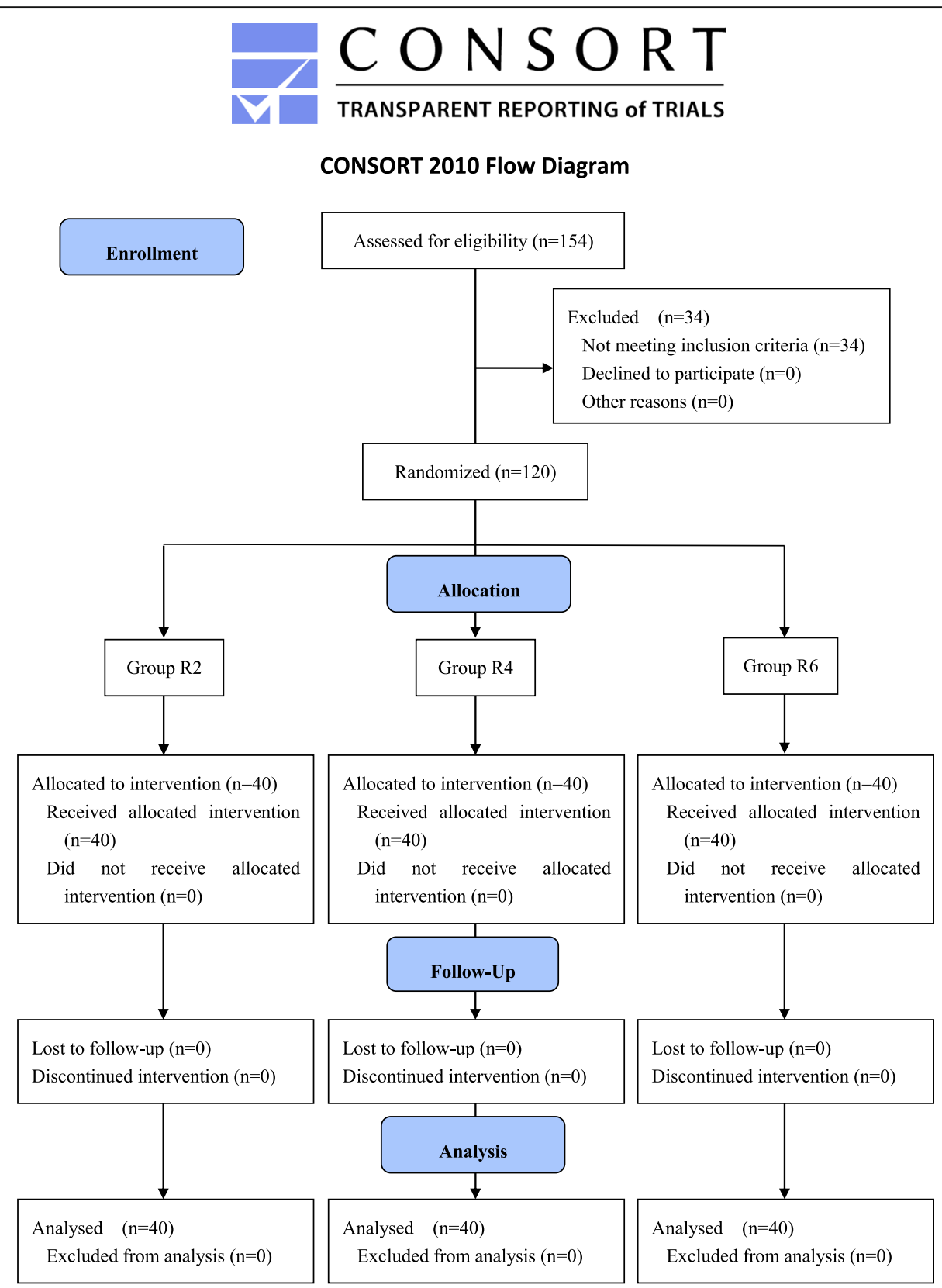

Fig. 1 Flow diagram of the structure of the study

the target concentration for $2 \mathrm{~min}$. During the whole procedure, remifentanil was kept at the initial given concentration; the anesthesia depth was mainly controlled by propofol, which was adjusted on the basis of the variety of $\mathrm{IOC}_{1}$ values. When $\mathrm{IOC}_{1}$ was maintained between 40 and 60 , the current propofol concentration was maintained. If the $\mathrm{IOC}_{1}$ values exceeded 60 , the propofol dose was increased by $0.5 \mu \mathrm{g} / \mathrm{mL}$ per adjustment, whereas if $\mathrm{IOC}_{1}$ went below 40 , the propofol concentration was decreased by $0.5 \mu \mathrm{g} / \mathrm{mL}$ per adjustment.

\section{IOC monitoring}

We used a multi-parameter anesthesia monitor (Angel60,000, Shenzhen Weihaokang Medical Technology Co., Ltd., Guangdong, China) for IOC monitoring. After skin cleaning with normal saline, the red, yellow, and green electrodes were connected to the center of the forehead, the top right of the brow ridge, and the cheekbone on the same side, respectively. $\mathrm{IOC}_{1}$ and $\mathrm{IOC}_{2}$ were recorded automatically every $15 \mathrm{~s}$. 


\section{Complications and management}

During the peri-operative period, hypotension was defined as a decrease in mean arterial pressure (MAP) over $20 \%$ or NIBP of not more than $90 / 60 \mathrm{~mm} \mathrm{Hg}$ [20, 21]; in this case, a dose of about 0.5 to $1 \mathrm{mg}$ of metaraminol (metaraminol bitartrate injection, batch number 17020438, Beijing Yokon Pharmaceutical Co., Ltd., Beijing, China) was injected. Hypertension was defined as MAP increased over $20 \%$ or NIBP of at least $140 / 90 \mathrm{~mm} \mathrm{Hg}$ [22, 23]; in this case, an injection of about 10 to $20 \mathrm{mg}$ of urapidil (urapidil injection, batch number 16112201, Guangzhou ImVin Pharmaceutical Co., Ltd., Guangzhou, China) was given. When heart rate (HR) went below 50 beats $/ \mathrm{min}$, bradycardia was diagnosed [24], and an injection of about 0.5 to $1 \mathrm{mg}$ of atropine (atropine sulfate injection, batch number 1701091, Tianjin Kingyork Pharmaceutical Co., Ltd., Tianjin, China) was given. When HR stayed above 100 beats/min, tachycardia was diagnosed [25], and a dose of about 0.5 to $1 \mathrm{mg} / \mathrm{kg}$ of esmolol (esmolol hydrochloride injection, batch number 6F0142C05, Qilu Pharmaceutical Co., Ltd., Jinan, China) was injected. Moreover, if $\mathrm{SpO}_{2}$ dropped below 95\%, the temporomandibular joint should be lifted; if $\mathrm{SpO}_{2}$ dropped below $90 \%$, hypoxemia was diagnosed [26, 27]; and if hypoxemia lasted over $2 \mathrm{~min}$, all drugs and operations must stop, assisted breathing with a balloon mask must be provided, and the trial must be terminated. In addition, the interval between pulling out the gastroscope and opening the eyes when calling the patient's name in a normal voice was defined as the awakening time $[28,29]$. Whether the patient could partially or totally remember the events during the whole general anesthesia period was defined as intra-operative awareness [30, 31].

\section{Sample size calculation}

The calculation of the sample size in this research was based on the literature reports related to remifentanil used in gastroscopy [13-15, 32, 33]. The average cases were about 32 to 42 patients in each group. Thus, we decided to enroll 40 cases in each group. Considering the possible loss of cases in the study (about 20\% to $30 \%$ ), we recruited a total of 154 patients (Fig. 1).

\section{Randomization and blinding}

The group allocation was based on a random number generated by a computer and divided by 3 ; if the remainder was 1 , the patient was allocated to the remifentanil $2 \mathrm{ng} / \mathrm{mL}$ group (group R2); if the remainder was 2, the patient was assigned to the remifentanil $4 \mathrm{ng} / \mathrm{mL}$ group (group R4); otherwise, the patient was assigned to the remifentanil $6 \mathrm{ng} / \mathrm{mL}$ group (group R6). The anesthesiologists involved in the practice of anesthesia knew the patient's group allocation, but all parameters were observed and recorded by another anesthesiologist who
Table 1 Demographics of the three groups

\begin{tabular}{lllll}
\hline Item & Group R2 & Group R4 & Group R6 & $P$ value \\
\hline Sex, male/female & $22 / 18$ & $24 / 16$ & $23 / 17$ & 0.903 \\
Age, years & $45 \pm 10$ & $43 \pm 10$ & $45 \pm 8$ & 0.442 \\
Height, cm & $164 \pm 9$ & $165 \pm 8$ & $164 \pm 8$ & 0.892 \\
Weight, kg & $62 \pm 10$ & $61 \pm 11$ & $60 \pm 9$ & 0.668 \\
Operation time, min & $18 \pm 5$ & $18 \pm 4$ & $18 \pm 4$ & 0.782 \\
\hline
\end{tabular}

was blind to the group allocation and did not take part in the implementation of anesthesia.

\section{Data collection}

The average target concentration of propofol and patient's awakening time were observed. The values of $\mathrm{IOC}_{1}, \mathrm{IOC}_{2}$, $\mathrm{MAP}, \mathrm{HR}$, and $\mathrm{SpO}_{2}$ were monitored during the entire course of therapy and were recorded at the following time points: $10 \mathrm{~min}$ after patients entered the endoscopy room $\left(\mathrm{T}_{0}\right)$, at the beginning of the gastroscopy $\left(\mathrm{T}_{1}\right)$, at the time of the polypectomy $\left(\mathrm{T}_{2}\right)$, at the end of the operation $\left(\mathrm{T}_{3}\right)$, and at the time the patient opened their eyes after being called by name $\left(\mathrm{T}_{4}\right)$. Peri-operative adverse reactions such as hypotension, hypertension, bradycardia, tachycardia, body movements, hypoxemia, interruption of therapy, nausea, vomiting, aspiration, and intra-operative awareness were also observed.

\section{Outcomes}

The primary outcomes were the dosage of propofol and remifentanil. The secondary outcomes were the variety of $\mathrm{IOC}_{1}$ and $\mathrm{IOC}_{2}$, patients' awakening time, and peri-operative adverse reactions such as hypotension, hypertension, bradycardia, tachycardia, body movements, hypoxemia, therapy interruption, nausea, vomiting, aspiration, and intra-operative awareness. Other outcomes were MAP, $\mathrm{HR}$, and $\mathrm{SpO}_{2}$ at different time points.

\section{Statistical analysis}

All data were analyzed by using the SPSS statistical package (SPSS 13.0 for Windows, Inc., Chicago, IL, USA) and were presented as mean \pm standard deviation, number, or percentage. Group comparisons about age, weight, height, operation time, propofol dosage, and awakening time were analyzed by using one-way analysis

Table 2 Comparison of propofol dosage and awakening time among groups

\begin{tabular}{lllll}
\hline Item & Group R2 & Group R4 & Group R6 & $P$ value \\
\hline $\begin{array}{llll}\text { Average propofol dosage, } \\
\mu \mathrm{g} / \mathrm{mL}\end{array}$ & $2.6 \pm 0.6$ & $2.2 \pm 0.6^{* *}$ & $2.1 \pm 0.5^{* *}$ & 0.001 \\
Awakening time, min & $3.1 \pm 1.1$ & $2.4 \pm 1.2^{*}$ & $2.5 \pm 1.2^{*}$ & 0.025 \\
\hline
\end{tabular}

Compared with group $\mathrm{R} 2,{ }^{*} P<0.05,{ }^{* *} P<0.01$ 
of variance (ANOVA). Values of $\mathrm{IOC}_{1}, \mathrm{IOC}_{2}, \mathrm{MAP}, \mathrm{HR}$, and $\mathrm{SpO}_{2}$ were measured by repeated-measures ANOVA. Categorical data were compared by using the chi-squared test or Fisher's exact test. A $P$ value of less than 0.05 was considered statistically significant.

\section{Results}

One hundred fifty-four patients scheduled for gastroscopic polypectomy were initially assessed for eligibility from February 22, 2017 to June 30, 2017. Thirty-four patients were excluded: 26 patients were excluded for being older than 60 years, three because of body weight exceeding $20 \%$ of the ideal body weight, three had tachycardia, one had bradycardia, and one had had upper airway infection in the previous 2 weeks. No severe adverse event leading to a termination of the study was observed. Therefore, altogether 120 patients (40 in each group) were enrolled in this study (Fig. 1).

\section{Demographic profile}

Elements of the patients' demographic profile, including sex, age, weight, height, and operation time, were similar among groups $(P>0.05)$ (Table 1$)$.

\section{Propofol dosage and awakening time}

As shown in Table 2, the average propofol dosage decreased significantly with the increasing dose of remifentanil $(P<0.01)$, and the awakening time in groups $\mathrm{R} 4$ and R6 also decreased when compared with group R2 $(P<0.05)$. However, there were no statistical differences in propofol dose and awakening time between groups R4 and R6 $(P>0.05)$.

\section{$\mathrm{IOC}_{1}$ in the three groups}

As shown in Table 3 and Fig. 2, $\mathrm{IOC}_{1}$ decreased significantly after anesthesia induction in all groups $(P<0.01)$ and then gradually increased to the baseline after the operation but was maintained at a comparatively lower state at $\mathrm{T}_{4}$ in group $\mathrm{R} 2(P<0.05)$. Compared with group R2, $\mathrm{IOC}_{1}$ was lower at $\mathrm{T}_{1}$ and $\mathrm{T}_{4}$ in group R4 (both $P<0.05$ ) and relatively lower at $\mathrm{T}_{1}, \mathrm{~T}_{2}, \mathrm{~T}_{3}$, and $\mathrm{T}_{4}$ in group $\mathrm{R} 6$ (all $P<0.05$ ). $\mathrm{IOC}_{1}$ was also lower at $\mathrm{T}_{1}$ and $\mathrm{T}_{2}$ in group R6 compared with group R4 (both $P<0.01$ ).

\section{$\mathrm{IOC}_{2}$ in the three groups}

As shown in Table 3 and Fig. 3, $\mathrm{IOC}_{2}$ dropped significantly after general anesthesia induction in the three groups $(P<0.01)$ and then came back to the basic level at $\mathrm{T}_{4}$. In group $\mathrm{R} 2, \mathrm{IOC}_{2}$ remained above 50 at $\mathrm{T}_{1}$ and $\mathrm{T}_{2}$. In group R6, $\mathrm{IOC}_{2}$ went below 30 at $\mathrm{T}_{1}$. Compared with group R2, $I_{2}$ was remarkably lower at $T_{1}, T_{2}$, and $T_{3}$ than that in groups R4 and R6 (all $P<0.01$ ). $\mathrm{IOC}_{2}$ was also relatively lower at $\mathrm{T}_{1}$ than that in group $\mathrm{R} 6$ compared with group R4 $(P<0.01)$.

\section{Peri-operative adverse reactions among groups}

As shown in Table 4, with the increasing dosage of remifentanil, the morbidity of hypertension and body movements declined, but the incidence of hypotension, bradycardia, and hypoxemia rose, and there were statistical differences in hypertension and hypoxemia between groups R2 and R6 $(P<0.05)$. However, no statistically significant differences in hypotension, bradycardia, tachycardia, and body movements were observed among the three groups $(P>0.05)$. Furthermore, no patient in any group had therapy interruption, nausea, vomiting, aspiration, or intra-operative awareness.

\section{MAP among groups}

Compared with $\mathrm{T}_{0}$, MAP decreased after anesthesia induction in all groups $(P<0.01)$ and gradually increased as the operation progressed but was still lower than the baseline value at $\mathrm{T}_{4}$ in groups $\mathrm{R} 2$ and $\mathrm{R} 6(P<0.01)$. Compared with group R2, MAP was comparatively lower at $\mathrm{T}_{1}$

Table 3 Comparison of index of consciousness among groups

\begin{tabular}{|c|c|c|c|c|c|}
\hline Item & Time point & Group R2 & Group R4 & Group R6 & $P$ value \\
\hline \multirow[t]{5}{*}{$\overline{\mathrm{IOC}_{1}}$} & $\mathrm{~T}_{0}$ & $98.0 \pm 1.5$ & $98.1 \pm 1.3$ & $97.7 \pm 1.3$ & 0.371 \\
\hline & $\mathrm{T}_{1}$ & $47.5 \pm 6.9^{2 \&}$ & $43.6 \pm 9.5^{8.8^{*}}$ & $38.5 \pm 7.27^{88^{* * \# \#}}$ & 0.000 \\
\hline & $\mathrm{T}_{2}$ & $49.7 \pm 7.1^{\& \&}$ & $46.7 \pm 8.8^{\& \&}$ & $42.0 \pm 6.1^{88^{* * \# \#}}$ & 0.000 \\
\hline & $T_{3}$ & $54.3 \pm 9.0^{8 \&}$ & $53.2 \pm 8.3^{2 \&}$ & $49.8 \pm 7.9^{88^{*}}$ & 0.046 \\
\hline & $\mathrm{T}_{4}$ & $95.8 \pm 4.5^{\&}$ & $97.7 \pm 1.4^{* *}$ & $97.5 \pm 1.5^{* *}$ & 0.006 \\
\hline \multirow[t]{5}{*}{$1 \mathrm{OC}_{2}$} & $\mathrm{~T}_{0}$ & $97.8 \pm 1.9^{8 \&}$ & $97.8 \pm 1.5$ & $98.0 \pm 1.2$ & 0.753 \\
\hline & $\mathrm{T}_{1}$ & $47.2 \pm 7.9^{8 \&}$ & $32.9 \pm 9.5^{88^{* *}}$ & $26.6 \pm 7.4^{88^{* * \# \#}}$ & 0.000 \\
\hline & $\mathrm{T}_{2}$ & $53.0 \pm 11.5^{2 \&}$ & $37.1 \pm 11.5^{28^{* *}}$ & $34.2 \pm 8.5^{28^{* *}}$ & 0.000 \\
\hline & $\mathrm{T}_{3}$ & $59.6 \pm 16.1^{8 \&}$ & $46.0 \pm 14.3^{88^{* *}}$ & $45.6 \pm 11.5^{88^{* *}}$ & 0.000 \\
\hline & $\mathrm{T}_{4}$ & $98.2 \pm 1.1$ & $98.0 \pm 0.9$ & $97.8 \pm 1.4$ & 0.274 \\
\hline
\end{tabular}

Compared with group $\mathrm{T}_{0},{ }^{\&} P<0.05$, ${ }^{\& \&} P<0.01$; compared with group $\mathrm{R} 2,{ }^{*} P<0.05,{ }^{* *} P<0.01$; compared with group $\mathrm{R} 4$, ${ }^{\#} P<0.05,{ }^{\# \#} P<0.01$ 


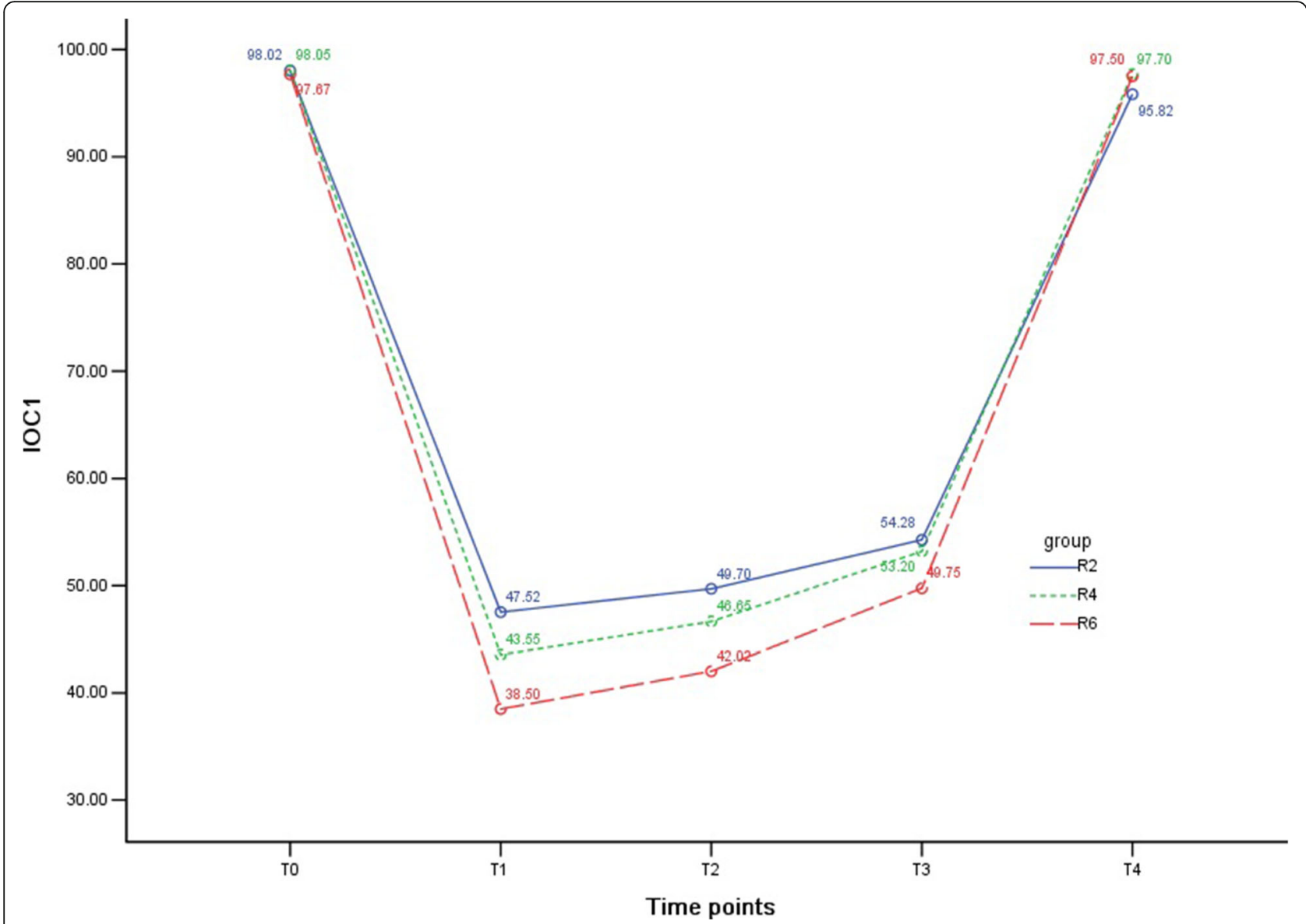

Fig. 2 Index of consciousness $1\left(I O C_{1}\right)$ in the three groups. The variety of $I O C_{1}$ at different time points in the three groups is shown

in group R4 $(P<0.05)$ and relatively lower at $\mathrm{T}_{1}, \mathrm{~T}_{2}$, and $\mathrm{T}_{3}$ in group R6 (all $P<0.01$ ) (Table 5 and Fig. 4).

\section{HR among groups}

HR in the three groups decreased after anesthesia induction, and compared with $\mathrm{T}_{0}$, the differences at $\mathrm{T}_{1}$ and $\mathrm{T}_{2}$ were statistically significant in groups $\mathrm{R} 2$ and $\mathrm{R} 4(P<0.05)$. However, there was no statistical difference among groups $(P>0.05)$ (Table 5 and Fig. 5$)$.

\section{$\mathrm{SpO}_{2}$ among groups}

Compared with $\mathrm{T}_{0}, \mathrm{SpO}_{2}$ at $\mathrm{T}_{1}$ and $\mathrm{T}_{2}$ in group $\mathrm{R} 2$ and at $\mathrm{T}_{1}, \mathrm{~T}_{2}$, and $\mathrm{T}_{3}$ in groups $\mathrm{R} 4$ and $\mathrm{R} 6$ decreased significantly (all $P<0.01$ ) but came back to the baseline at $\mathrm{T}_{4}$. $\mathrm{SpO}_{2}$ was relatively lower at $\mathrm{T}_{1}$ in group $\mathrm{R} 6$ compared with group R2 $(P<0.01)$ (Table 5 and Fig. 6$)$.

\section{Discussion}

With the widespread use of target-controlled infusion and anesthesia depth monitoring, accurate anesthesia is gradually becoming possible $[34,35]$. The aim of this study was to select a relatively ideal remifentanil target concentration in gastric polypectomy under sedation and analgesia monitoring to help the anesthesiologists lessen the side effects of this agent.

Gastroscopic polypectomy has been performed under general anesthesia for years. The most common anesthetic used in this procedure is propofol [36]; however, there is no analgesic effect of this agent, but the injection pain incidence is as high as about $24 \%$ to $86 \%$ [37-39], which leads to a reduction in patients' comfort and cooperation. Remifentanil is a potent narcotic analgesic with rapid onset, high clearance, and short duration [40]. As research progressed, it is reported that the combination of remifentanil and propofol not only can effectively reduce the incidence of propofol-induced pain but also can reduce the dosage of propofol, shorten patients' recovery time, and enhance patients' satisfaction in endoscopy [32, 40]. However, the usage of remifentanil varies widely in different studies (for instance, a target concentration of about 0.72 to $3.19 \mathrm{ng} / \mathrm{mL}$ [13], a single dose from 0.2 to $0.5 \mu \mathrm{g} / \mathrm{kg}[14,15]$, and a continuous infusion rate of $6 \mu \mathrm{g} \cdot \mathrm{kg}^{-1} \cdot \mathrm{h}^{-1}$ [33]). As both propofol and remifentanil may cause some dose-dependent respiratory and cardiovascular depression, leading to 


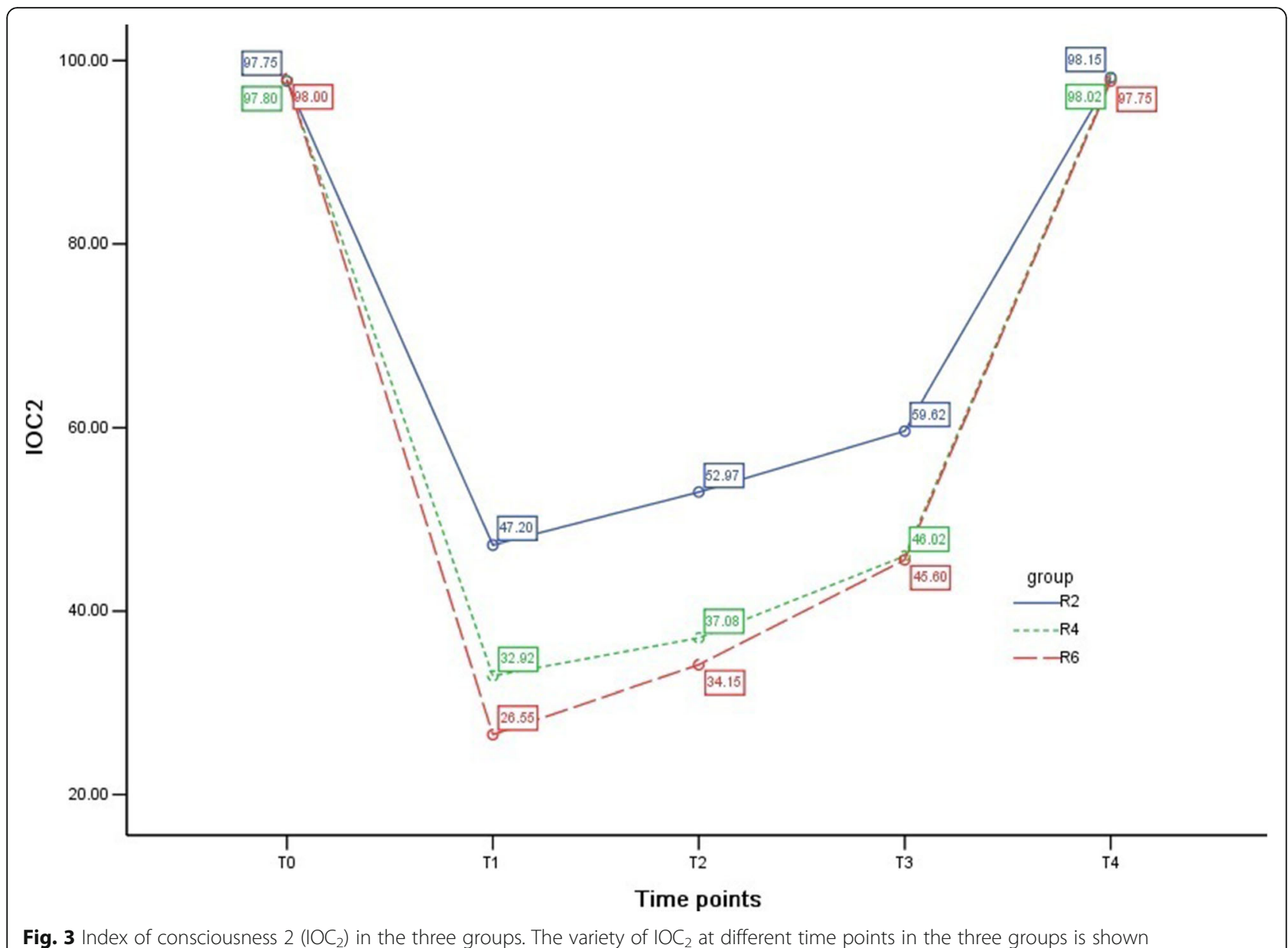

hypoxemia and hemodynamic instability [40, 41], it is important to have safe and convenient anesthesia depth monitoring to help control anesthetic dose such as remifentanil target concentration during endoscopic therapy.

IOC is generated by the conversion of electroencephalogram (EEG) signals with a symbolic dynamics method, which finally turned into numerical values via an Adaptive Neurofuzzy Inference System that established the relationship between variables on the basis of a non-restricted mathematical structure [42, 43]. As previous research has shown, $I_{1}$ can accurately reflect the patient's sedation state with good consistency with bispectral index [44].

Table 4 Peri-operative adverse reactions

\begin{tabular}{lllll}
\hline Item & Group R2 & Group R4 & Group R6 & $12(30.0 \%)$ \\
\hline Hypotension (\%) & $7(17.5 \%)$ & $8(20.0 \%)$ & $0(0)^{*}$ \\
Hypertension (\%) & $6(15.0 \%)$ & $4(10.0 \%)$ & $8(20.0 \%)$ & 0.367 \\
Bradycardia (\%) & $5(12.5 \%)$ & $7(17.5 \%)$ & $5(15.0 \%)$ & 0.047 \\
Tachycardia (\%) & $6(15.0 \%)$ & $5(12.5 \%)$ & $1(2.5 \%)$ & $8(20.0 \%)^{*}$ \\
Body movement(\%) & $2(5.0 \%)$ & $4(10.0 \%)$ & $0(0)$ & 0.957 \\
Hypoxemia (\%) & $1(2.5 \%)$ & $0(0)$ & $0(0)$ & 0.359 \\
Therapy interruption (\%) & $0(0)$ & $0(0)$ & $0(0)$ & 0.041 \\
Nausea (\%) & $0(0)$ & $0(0)$ & $0(0)$ & 1.000 \\
Vomiting (\%) & $0(0)$ & $0(0)$ & 1.000 \\
Aspiration (\%) & $0(0)$ & $0(0)$ & 1.000 \\
Intra-operative awareness (\%) & $0(0)$ & & 1.000 \\
\hline
\end{tabular}

Compared with group R2, ${ }^{*} P<0.05$ 
Table 5 Comparison of MAP, HR, and $\mathrm{SpO}_{2}$ in the three groups

\begin{tabular}{|c|c|c|c|c|c|}
\hline Item & Time point & Group R2 & Group R4 & Group R6 & $P$ \\
\hline \multirow[t]{5}{*}{ MAP, mm Hg } & $\mathrm{T}_{0}$ & $89.7 \pm 8.7$ & $85.8 \pm 9.5$ & $87.2 \pm 9.1$ & 0.162 \\
\hline & $\mathrm{T}_{1}$ & $76.4 \pm 7.7^{8 \&}$ & $73.1 \pm 7.6^{88^{*}}$ & $71.8 \pm 6.9^{88^{* *}}$ & 0.018 \\
\hline & $\mathrm{T}_{2}$ & $79.4 \pm 9.5^{8 \&}$ & $76.5 \pm 10.8^{\& \&}$ & $73.2 \pm 6.5^{88^{* *}}$ & 0.010 \\
\hline & $T_{3}$ & $84.6 \pm 13.4$ & $80.6 \pm 13.2$ & $76.9 \pm 7.2^{88^{* *}}$ & 0.014 \\
\hline & $\mathrm{T}_{4}$ & $82.6 \pm 8.8^{\& \&}$ & $83.1 \pm 9.5$ & $80.7 \pm 6.4^{8 \&}$ & 0.392 \\
\hline \multirow[t]{5}{*}{$\mathrm{HR}$, beats/min } & $T_{0}$ & $80.0 \pm 11.3$ & $77.3 \pm 10.0$ & $78.7 \pm 10.4$ & 0.511 \\
\hline & $\mathrm{T}_{1}$ & $71.1 \pm 7.9^{8 \&}$ & $69.3 \pm 7.1^{8 \&}$ & $72.6 \pm 14.2$ & 0.345 \\
\hline & $T_{2}$ & $72.8 \pm 10.9^{\&}$ & $71.8 \pm 12.0^{\&}$ & $75.4 \pm 14.0$ & 0.400 \\
\hline & $T_{3}$ & $75.3 \pm 10.0$ & $75.8 \pm 14.5$ & $78.2 \pm 11.3$ & 0.526 \\
\hline & $\mathrm{T}_{4}$ & $76.7 \pm 7.9$ & $78.2 \pm 10.8$ & $76.1 \pm 9.5$ & 0.601 \\
\hline \multirow[t]{5}{*}{$\mathrm{SpO}_{2}, \%$} & $\mathrm{~T}_{0}$ & $97.8 \pm 1.1$ & $97.9 \pm 1.1$ & $98.1 \pm 1.1$ & 0.476 \\
\hline & $\mathrm{T}_{1}$ & $96.6 \pm 2.8^{8}$ & $95.5 \pm 3.9^{2 \&}$ & $93.8 \pm 4.8^{88^{* *}}$ & 0.006 \\
\hline & $\mathrm{T}_{2}$ & $96.2 \pm 2.4^{8 \&}$ & $95.7 \pm 2.9^{2 \&}$ & $95.0 \pm 3.8^{8 \&}$ & 0.200 \\
\hline & $\mathrm{T}_{3}$ & $96.9 \pm 2.4$ & $96.5 \pm 2.3^{2 \&}$ & $96.4 \pm 2.2^{2 \&}$ & 0.658 \\
\hline & $\mathrm{T}_{4}$ & $97.8 \pm 1.2$ & $98.0 \pm 0.9$ & $98.1 \pm 0.8$ & 0.482 \\
\hline
\end{tabular}

Compared with group $\mathrm{T}_{0},{ }^{\&} P<0.05,{ }^{\& \&} P<0.01$; compared with group $\mathrm{R} 2,{ }^{*} P<0.05,{ }^{* *} P<0.01$

Abbreviations: $H R$ heart rate, MAP mean arterial pressure, $\mathrm{SpO}_{2}$ pulse oxygen saturation

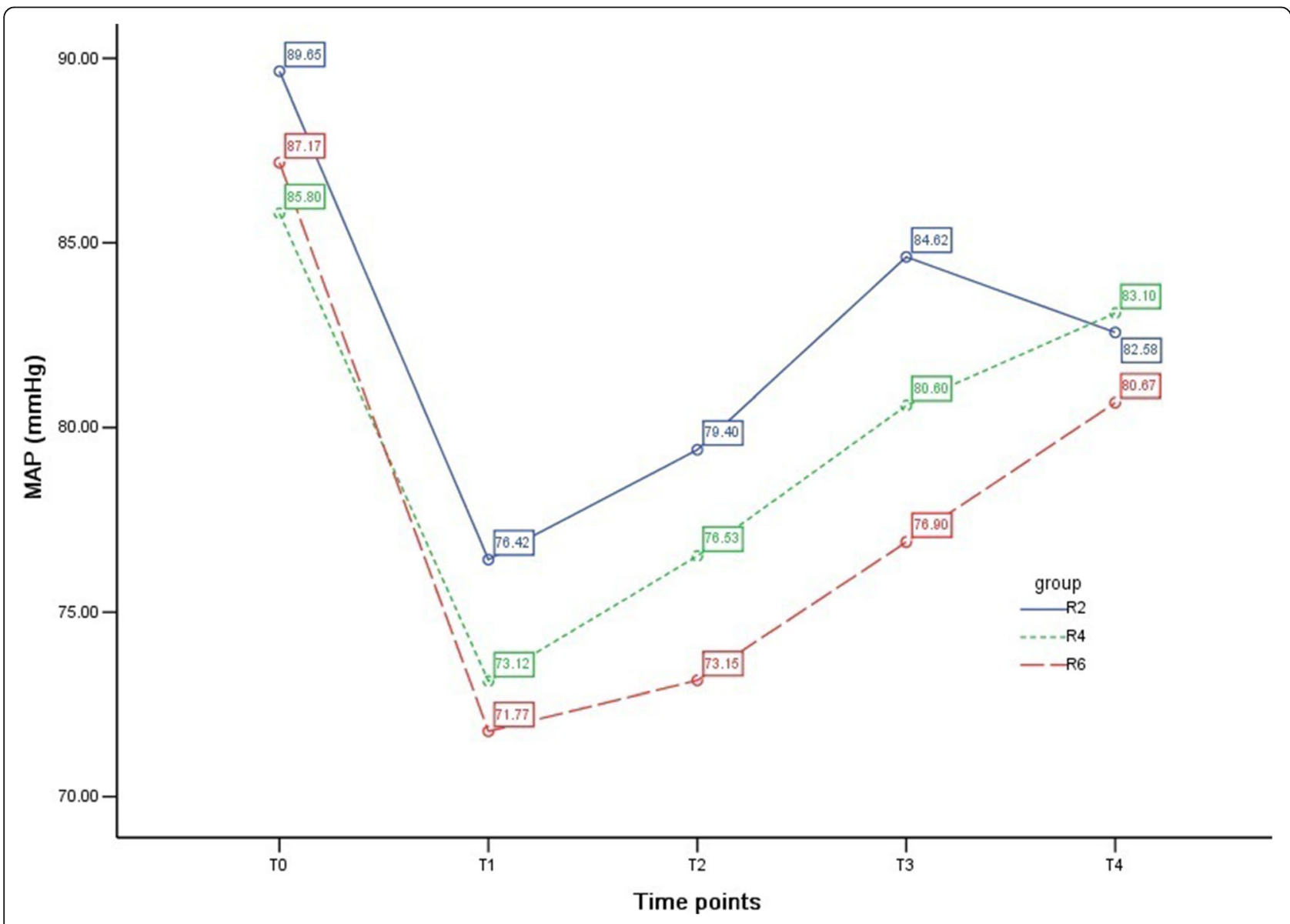

Fig. 4 Mean arterial pressure (MAP) among groups. The variety of MAP at different time points in the three groups is shown 


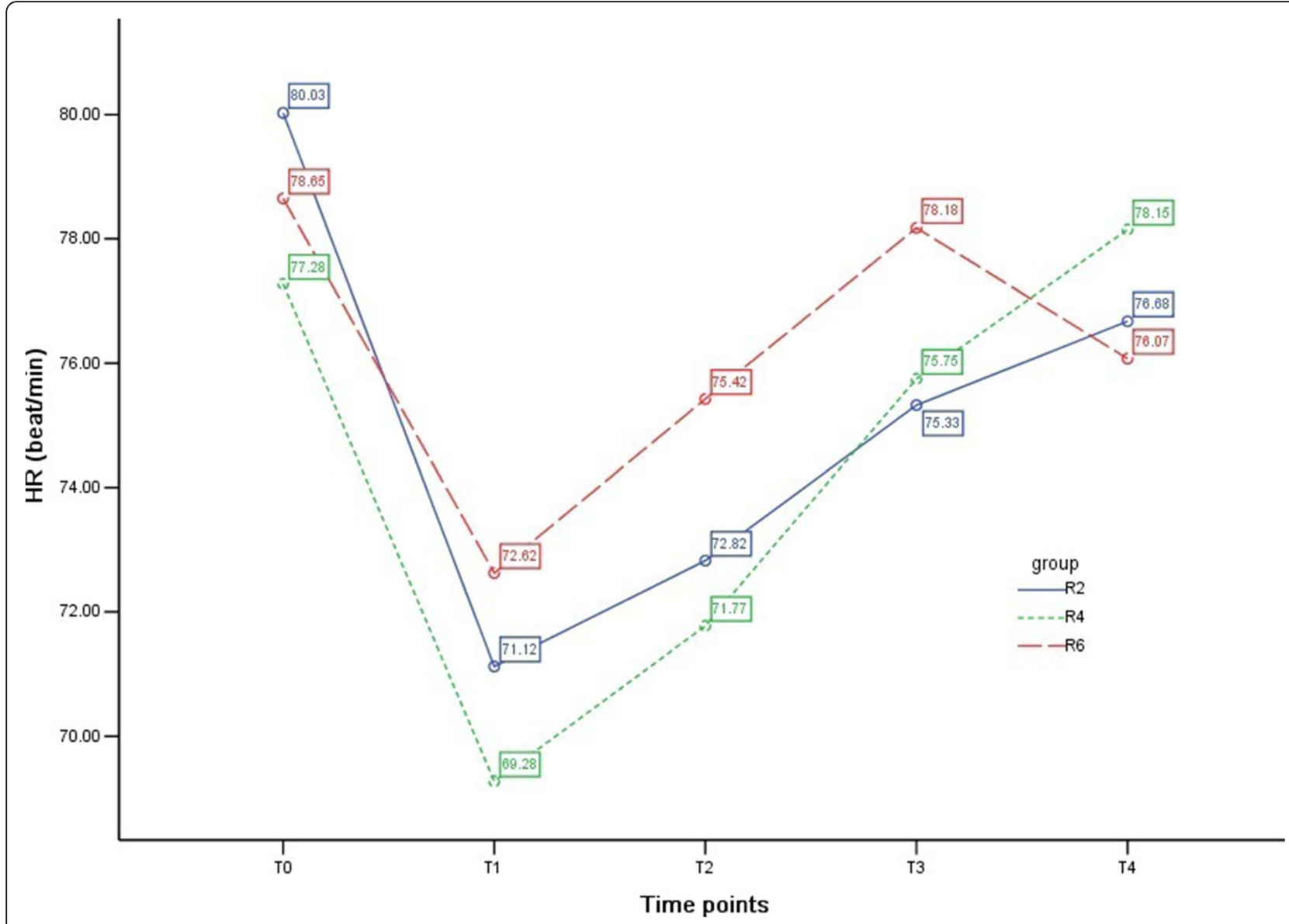

Fig. 5 Heart rate $(H R)$ among groups. The variety of $H R$ at different time points in the three groups is shown

$\mathrm{IOC}_{1}$ ranges from 0 to 99 ; when the value exceeds 80 , the patient is generally considered to be awake; about 60 to 80 indicates mild sedation, which reminds the anesthesiologist to add sedative agents; about 40 to 60 represents appropriate sedative depth; and less than 40 indicates immoderate depression [45]. $\mathrm{IOC}_{2}$ is derived from $\mathrm{IOC}_{1}$, also ranges from 0 to 99 , but mainly reflects the degree of analgesia; a value beyond 50 usually signifies inadequate analgesia, 30 to 50 indicates a suitable analgesia state, and below 30 represents excessive analgesic effects [17]. This trial was designed to provide a better and safer analgesia project by comparing the variety of $\mathrm{IOC}_{2}$ and the occurrence rate of adverse events with different remifentanil dosages in gastroscopic polypectomy.

Like the constantly changing curves of EEG, the values of $\mathrm{IOC}_{1}$ and $\mathrm{IOC}_{2}$ fluctuate slightly even at the same concentration of anesthetics during the maintenance of general anesthesia. Given the time delay effect of IOC, it is recommended that the best opportunity to adjust anesthetics was when the values surpass their current level over 20 within $1 \mathrm{~min}$ or went beyond their recommended appropriate range for more than $2 \min [17,45]$.
In this research, each propofol adjustment was guided by the sudden fluctuation of $\mathrm{IOC}_{1}$ over 20 within 1 min or remaining above 60 or below 40 for more than $2 \mathrm{~min}$. The results showed that all patients completed the endoscopic treatment successfully, no one had temporary change of treatment, and no patient appeared to have intra-operative awareness, indicating that a plasma concentration of remifentanil of about $2 \mu \mathrm{g} / \mathrm{mL}$ to $6 \mathrm{ng} / \mathrm{mL}$ could be used safely in gastric polypectomy. Nevertheless, our study also showed that the incidence of respiratory and cardiovascular depressions increased with the increase of remifentanil dose, indicating that the maximal dosage of remifentanil should be controlled.

In group R2, only one patient had hypoxemia, and the incidence of each single indicator of cardiovascular instability was no more than $20 \%$, suggesting that a dose of remifentanil $2 \mathrm{ng} / \mathrm{mL}$ was safe during gastroscopic treatment. However, with the intense stimulation of the therapy, although $\mathrm{IOC}_{1}$ remained below 60 , this analgesia dosage was relatively insufficient because the average value of $\mathrm{IOC}_{2}$ was above 50 and two patients appeared to have body movements during the treatment, 


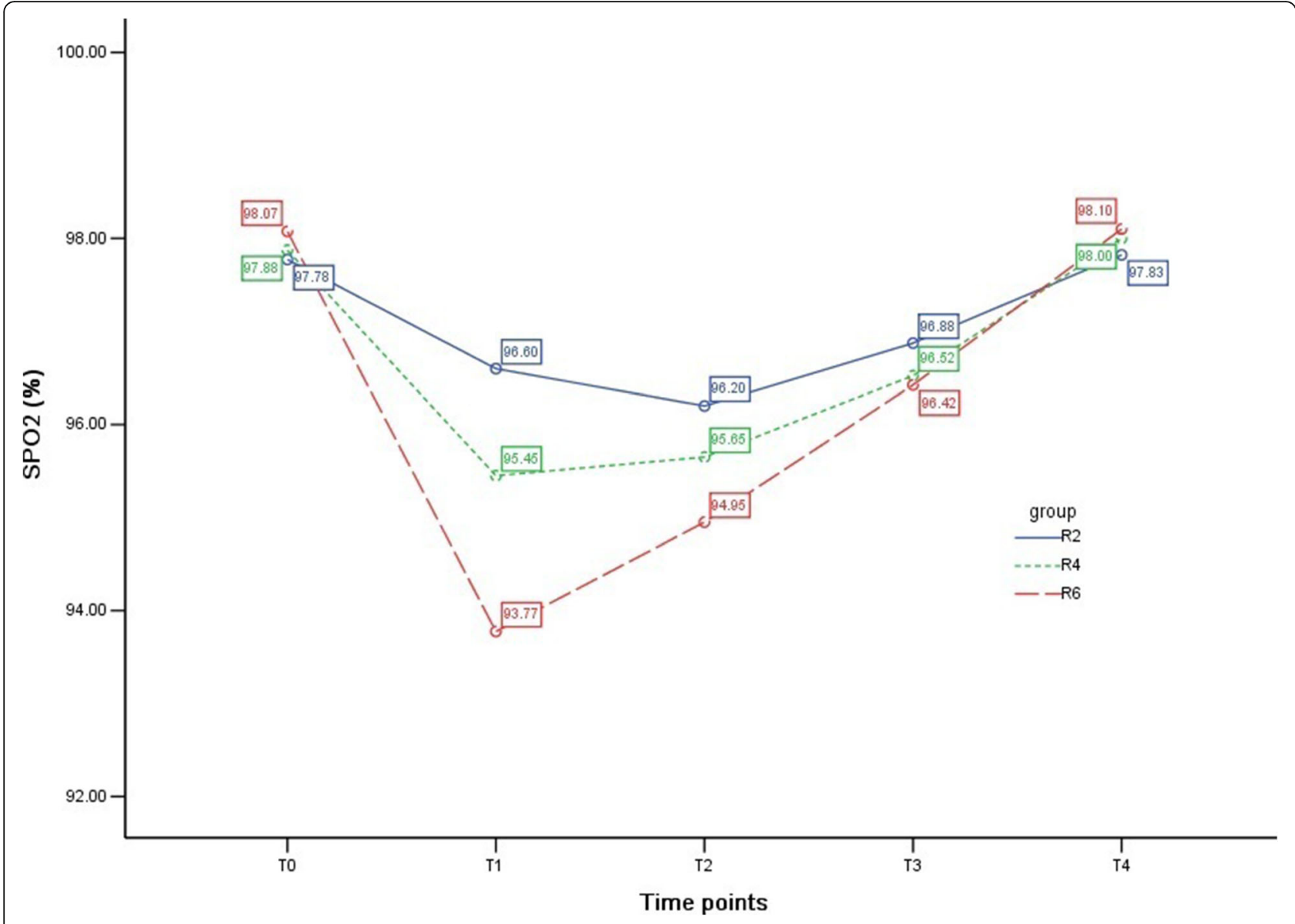

Fig. 6 Pulse oxygen saturation $\left(\mathrm{SpO}_{2}\right)$ among groups. The variety of $\mathrm{SpO}_{2}$ at different time points in the three groups is shown

indicating that a higher dosage of remifentanil was needed during the period of the resection of gastric polyps under gastroscope.

In group R6, no one experienced hypertension or body movements, signifying a thorough suppression of the adverse nervous reflex. However, with the dose-dependent inhibition on respiratory and cycle systems of remifentanil, the incidence of hypoxemia and bradycardia increased up to $20 \%$, the occurrence of hypotension even reached as high as $30 \%$, and $\mathrm{IOC}_{2}$ dropped to below 30 at $\mathrm{T}_{2}$, revealing that a concentration of remifentanil $6 \mathrm{ng} / \mathrm{mL}$ was excessive. On the other hand, with the potent analgesia and short-acting characteristics of remifentanil, the average dose of propofol decreased and therefore the patient's awakening time was not delayed.

Compared with patients in groups R2 and R6, those in group R4 showed comparatively stable breathing and hemodynamics, and $\mathrm{IOC}_{1}$ and $\mathrm{IOC}_{2}$ were maintained at the recommended appropriate ranges. Thus, a plasma concentration of remifentanil $4 \mathrm{ng} / \mathrm{mL}$ may be the comparatively ideal dose in gastroscopic polypectomy.
There were some limitations in our study. To begin with, we chose patients undergoing gastroscopic polypectomy because pain intensity was relatively stable throughout the duration of therapy, and the impacts from operation interference among patients were tiny. However, the results were limited and could not be directly extended to other surgeries, and advancement should be made in other surgeries and treatments. In addition, the calculation of the sample size in this study was based on the literature reports related to remifentanil used in gastroscopy. A larger sample and more remifentanil concentration gradients are necessary to help select a more accurate dosage. Moreover, our study found that there was about a 1-min delay in the value reduction of $\mathrm{IOC}_{2}$ after anesthesia induction and that the $\mathrm{IOC}_{2}$ value might decline with the decrease of $\mathrm{IOC}_{1}$, even before the injection of remifentanil, indicating that changes in $\mathrm{IOC}_{2}$ were somehow affected by $\mathrm{IOC}_{1}$. Therefore, some other anesthesia depth-monitoring parameters (for instance, the bispectral index) should be included in future studies to correlate the parameter with $\mathrm{IOC}_{2}$. Finally, the remifentanil concentration in this study was invariable; 
other methods of anesthetic administration such as "Adjust the dosage of remifentanil according to the changes of $\mathrm{IOC}_{1}$ and $\mathrm{IOC}_{2}$ during the treatment" should be examined in future studies to help develop a more ideal concentration range of remifentanil.

\section{Conclusions}

In brief, the combination of remifentanil and IOC monitoring is safe, and with the help of IOC monitoring, we found that a target concentration of remifentanil $4 \mathrm{ng} / \mathrm{mL}$ is comparatively ideal in patients under gastroscopic polypectomy.

\section{Abbreviations \\ ANOVA: Analysis of variance; EEG: Electroencephalogram; HR: Heart rate; IOC: Index of consciousness; IOC 1 : Index of consciousness $1 ; 10 C_{2}$ : Index of consciousness 2; MAP: Mean arterial pressure; NIBP: Non-invasive blood pressure; $\mathrm{SpO}_{2}$ : Pulse oxygen saturation}

\section{Acknowledgements}

We would like to thank the Journal of Zhejiang University English Polishing Service (http://www.jzus.zju.edu.cn/polish.php) for their help with English usage of this study.

\section{Availability of data and materials}

This study was recorded on ResMan Research Manager:

http://www.medresman.org/pub/cn/proj/projectshshow.aspx?proj=110.

\section{Authors' contributions}

$M L$ and HW conceived the project and helped design the study. ML, HW and DY performed general anesthesia and drafted the manuscript. FL contributed to and revised the manuscript. ZL and SW collected and analyzed the data. $\mathrm{RH}$ accepted direct responsibility for the manuscript that resulted from this study. All authors approved the final submission.

\section{Ethics approval and consent to participate}

This study was approved by the medical ethics committee of Shenzhen Third People's Hospital (No. 29 Bulan Road, Longgang district, Shenzhen, Guangdong, China, approval number 2016-001; October 17, 2016). Written informed consent was obtained and documented for all participants.

\section{Consent for publication}

Not applicable.

\section{Competing interests}

The authors declare that they have no competing interests.

\section{Publisher's Note}

Springer Nature remains neutral with regard to jurisdictional claims in published maps and institutional affiliations.

\section{Author details}

'Department of Anesthesiology, Shenzhen Third People's Hospital, No. 29 Bulan Road, Longgang District, Shenzhen 518112, Guangdong, China. 2Department of Endoscopy, Shenzhen Third People's Hospital, No. 29 Bulan Road, Longgang District, Shenzhen 518112, Guangdong, China. ${ }^{3}$ Department of Anesthesiology, Zhujiang Hospital of Southern Medical University, No. 253 Middle Industrial Avenue, Haizhu District, Guangzhou 518112, Guangdong, China.
}

Received: 12 October 2017 Accepted: 4 July 2018

Published online: 18 July 2018

\section{References}

1. Argüello Viúdez L, Córdova H, Uchima H, Sánchez-Montes C, Ginès À, Araujo I, et al. Gastric polyps: retrospective analysis of 41,253 upper endoscopies. Gastroenterol Hepatol. 2017;40(8):507-14. https://doi.org/10. 1016/j.gastrohep.2017.01.003.

2. Barbosa SHB, Filho LGC, Franco LM, Junior VJT, Nobre E Souza MÂ, Souza MHLP. Agreement between different pathologists in histopathologic diagnosis of 128 gastric polyps. Arq Gastroenterol. 2017;54(3):263-6. https:// doi.org/10.1590/S0004-2803.201700000-29.

3. Chang WH, Shih SC, Wang HY, Chang CW, Chen CJ, Chen MJ. Acquired hyperplastic gastric polyps after treatment of ulcer. J Formos Med Assoc. 2010;109(8):567-73. https://doi.org/10.1016/S0929-6646(10)60093-9.

4. Chen MJ, Lin CC, Liu CY, Chen CJ, Chang CW, Chang CW, et al. Training gastroenterology fellows to perform gastric polypectomy using a novel ex vivo model. World J Gastroenterol. 2011;17(41):4619-24. https://doi.org/10. 3748/wjg.v17.i41.4619.

5. Xiao Q, Yang Y, Zhou Y, Guo Y, Ao X, Han R, et al. Comparison of Nasopharyngeal Airway Device and Nasal Oxygen Tube in Obese Patients Undergoing Intravenous Anesthesia for Gastroscopy: A Prospective and Randomized Study. Gastroenterol Res Pract. 2016;2016:2641257. https://doi. org/10.1155/2016/2641257

6. Meining A, Semmler V, Kassem AM, Sander R, Frankenberger U, Burzin $M$, et al. The effect of sedation on the quality of upper gastrointestinal endoscopy: an investigator-blinded, randomized study comparing propofol with midazolam Endoscopy. 2007;39(4):345-9. https://doi.org/10.1055/s-2006-945195.

7. Shen XC, Ao X, Cao Y, Lan L, Liu XM, Sun WJ, et al. Etomidate-remifentanil is more suitable for monitored anesthesia care during gastroscopy in older patients than propofol-remifentanil. Med Sci Monit. 2015;21:1-8. https://doi. org/10.12659/MSM.891183.

8. Adams MA, Prenovost KM, Dominitz JA, Kerr EA, Krein SL, Saini SD, et al. National Trends in Use of Monitored Anesthesia Care for Outpatient Gastrointestinal Endoscopy in the Veterans Health Administration. JAMA Intern Med. 2017;177(3):436-8. https://doi.org/10.1001/jamainternmed.2016.8566.

9. Ye L, Xiao X, Zhu L. The comparison of etomidate and Propofol anesthesia in patients undergoing gastrointestinal endoscopy: a systematic review and meta-analysis. Surg Laparosc Endosc Percutan Tech. 2017;27(1):1-7. https:// doi.org/10.1097/SLE.0000000000000373.

10. Meng QT, Cao C, Liu HM, Xia ZY, Li W, Tang LH, et al. Safety and efficacy of etomidate and propofol anesthesia in elderly patients undergoing gastroscopy: a double-blind randomized clinical study. Exp Ther Med. 2016; 12(3):1515-24. https://doi.org/10.3892/etm.2016.3475.

11. Goudra B, Singh PM. Anesthesia for gastrointestinal endoscopy: a subspecialty in evolution? Saudi J Anaesth. 2015;9(3):237-8. https://doi.org/ 10.4103/1658-354X.154691.

12. Goudra BG, Singh PM. Propofol alternatives in gastrointestinal endoscopy anesthesia. Saudi J Anaesth. 2014;8(4):540-5. https://doi.org/10.4103/1658354X.140893.

13. Borrat X, Valencia JF, Magrans R, Gimenez-Mila M, Mellado R, Sendino O, et al. Sedation-analgesia with propofol and remifentanil: concentrations required to avoid gag reflex in upper gastrointestinal endoscopy. Anesth Analg. 2015;121(1):90-6. https://doi.org/10.1213/ANE.0000000000000756.

14. Xu ZY, Wang X, Si YY, Wu JC, Zuo YX, Xue FS, et al. Intravenous remifentanil and propofol for gastroscopy. J Clin Anesth. 2008;20(5):352-5. https://doi. org/10.1016/j.jclinane.2008.03.006

15. Uliana GN, Tambara EM, Baretta GA. Use of remifentanil to reduce propofol injection pain and the required propofol dose in upper digestive tract endoscopy diagnostic tests. Braz J Anesthesiol. 2015;65(6):437-44. https:// doi.org/10.1016/j.bjane.2014.12.001.

16. Jensen EW, Jospin M, Gambus PL, Vallverdu M, Caminal P. Validation of the index of consciousness (loC) during sedation/analgesia for ultrasonographic endoscopy. Conf Proc IEEE Eng Med Biol Soc. 2008;2008:5552-5. https://doi. org/10.1109/IEMBS.2008.4650472

17. Wu G, Zhang L, Wang X, Yu A, Zhang Z, Yu J. Effects of indexes of consciousness (loC1 and loC2) monitoring on remifentanil dosage in modified radical mastectomy: a randomized trial. Trials. 2016;17(1):167. https://doi.org/10.1186/s13063-016-1298-0.

18. Nunes RR, Fonseca NM, Simões CM, Rosa DM, Silva ED, Cavalcante SL, et al. Brazilian consensus on anesthetic depth monitoring. Braz J Anesthesiol. 2015:65(6):427-36. https://doi.org/10.1016/j.bjane.2015.10.001.

19. Park SW, Lee $H$, Ahn H. Bispectral index versus standard monitoring in sedation for endoscopic procedures: a systematic review and meta-analysis. Dig Dis Sci. 2016;61(3):814-24. https://doi.org/10.1007/s10620-015-3945-9.

20. Walsh M, Devereaux PJ, Garg AX, Kurz A, Turan A, Rodseth RN, et al. Relationship between intraoperative mean arterial pressure and clinical 
outcomes after noncardiac surgery: toward an empirical definition of hypotension. Anesthesiology. 2013;119(3):507-15. https://doi.org/10.1097/ ALN.0b013e3182a10e26.

21. Kalezic N, Stojanovic M, Ladjevic N, Markovic D, Paunovic I, Palibrk I, et al. Risk factors for intraoperative hypotension during thyroid surgery. Med Sci Monit. 2013;19:236-41. https://doi.org/10.12659/MSM.883869.

22. O'Shaughnessy MA, Adams JE. Perioperative Management of Hypertension in Hand Surgery Patients. J Hand Surg Am. 2015;40(8):1684-7. https://doi. org/10.1016/j.jhsa.2015.03.027.

23. Dewdney A, Cunningham D, Barbachano Y, Chau I. Correlation of bevacizumab-induced hypertension and outcome in the BOXER study, a phase II study of capecitabine, oxaliplatin (CAPOX) plus bevacizumab as peri-operative treatment in 45 patients with poor-risk colorectal liver-only metastases unsuitable for upfront resection. Br J Cancer. 2012;106(11):171821. https://doi.org/10.1038/bjc.2012.152.

24. Trappe HJ. ECG results: tips and tricks for the correct diagnosis : bradycardia and tachycardia rhythm disorders. Herz. 2018;43(2):177-94. https://doi.org/ 10.1007/s00059-018-4684-4.

25. Kurokochi N. Age-corrected intraoperative tachycardia correlates with postoperative electrocardiographic alterations. J Anesth. 2001;15(1):11-6. https://doi.org/10.1007/s005400170045.

26. Rozé H, Lafargue M, Ouattara A. Case scenario: Management of intraoperative hypoxemia during one-lung ventilation. Anesthesiology. 2011; 114(1):167-74. https://doi.org/10.1097/ALN.0b013e3182023ed3.

27. de Graaff JC, Bijker JB, Kappen TH, van Wolfswinkel L, Zuithoff NP, Kalkman CJ. Incidence of intraoperative hypoxemia in children in relation to age. Anesth Analg. 2013;117(1):169-75. https://doi.org/10.1213/ANE. Ob013e31829332b5.

28. Kudielka BM, Kirschbaum C. Awakening cortisol responses are influenced by health status and awakening time but not by menstrual cycle phase. Psychoneuroendocrinology. 2003;28(1):35-47. https://doi.org/10.1016/S03064530(02)00008-2

29. Goyagi T, Tanaka M, Nishikawa T. Oral clonidine premedication reduces induction dose and prolongs awakening time from propofol-nitrous oxide anesthesia. Can J Anaesth. 1999;46(9):894-6. https://doi.org/10.1007/BF03012982.

30. Mashour GA, Avidan MS. Intraoperative awareness: controversies and noncontroversies. Br J Anaesth. 2015;115(Suppl 1):i20-6. https://doi.org/10.1093/ bja/aev034.

31. Singla $\mathrm{D}$, Mangla $\mathrm{M}$. Incidence of awareness with recall under general anesthesia in rural India: an observational study. Anesth Essays Res. 2017; 11(2):489-94. https://doi.org/10.4103/aer.AER_44_17.

32. Sajedi P, Rahimian A, Khalili G. Comparative evaluation between two methods of induced hypotension with infusion of remifentanil and labetalol during sinus endoscopy. J Res Pharm Pract. 2016;5(4):264-71. https://doi. org/10.4103/2279-042X.192463.

33. Kim N, Yoo YC, Lee SK, Kim H, Ju HM, Min KT. Comparison of the efficacy and safety of sedation between dexmedetomidine-remifentanil and propofol-remifentanil during endoscopic submucosal dissection. World J Gastroenterol. 2015;21(12):3671-8. https://doi.org/10.3748/wjg.v21.i12.3671.

34. Shoushtarian M, Sahinovic MM, Absalom AR, Kalmar AF, Vereecke HE, Liley DT, et al. Comparisons of electroencephalographically derived measures of hypnosis and Antinociception in response to standardized stimuli during target-controlled Propofol-remifentanil anesthesia. Anesth Analg. 2016; 122(2):382-92. https://doi.org/10.1213/ANE.0000000000001029.

35. Shalbaf R, Behnam H, Sleigh JW, Steyn-Ross A, Voss $\sqcup$. Monitoring the depth of anesthesia using entropy features and an artificial neural network. J Neurosci Methods. 2013;218(1):17-24. https://doi.org/10.1016/j.jneumeth.2013.03.008

36. Wadhwa V, Issa D, Garg S, Lopez R, Sanaka MR, Vargo JJ. Similar risk of cardiopulmonary adverse events between Propofol and traditional Anesthesiafor gastrointestinal endoscopy: a systematic review and metaanalysis. Clin Gastroenterol Hepatol. 2017;15(2):194-206. https://doi.org/10. 1016/j.cgh.2016.07.013.

37. Madan HK, Singh R, Sodhi GS. Comparsion of Intravenous Lignocaine, Tramadol and Keterolac for Attenuation of Propofollnjection Pain. J Clin Diagn Res. 2016;10(7):UC05-8. https:/doi.org/10.7860/JCDR/2016/20444.8118.

38. Pei S, Zhou C, Zhu Y, Huang B. Efficacy of ondansetron for the prevention of propofol injection pain: a meta-analysis. J Pain Res. 2017;10:445-50. https://doi.org/10.2147/JPR.S128992.

39. Youn AM, Hsu TM. Heated carrier fluids in decreasing propofol injection pain: a randomized, controlled trial. Korean J Anesthesiol. 2017;70(1):33-8. https://doi.org/10.4097/kjae.2017.70.1.33.
40. Abu-Shahwan I, Mack D. Propofol and remifentanil for deep sedation in children undergoing gastrointestinal endoscopy. Paediatr Anaesth. 2007; 17(5):460-3. https://doi.org/10.1111/j.1460-9592.2006.02132.x.

41. Cong Y, Sun X. Mask adaptor--a novel method of positive pressure ventilation during propofol deep sedation for upper Gl endoscopy. Gastrointest Endosc. 2008;68(1):127-31. https://doi.org/10.1016/j.gie.2007.12.050

42. Revuelta M, Paniagua P, Campos JM, Fernández JA, Martínez A, Jospin M, et al. Validation of the index of consciousness during sevoflurane and remifentanil anaesthesia: a comparison with the bispectral index and the cerebral state index. Br J Anaesth. 2008;101(5):653-8. https://doi.org/10. 1093/bja/aen245.

43. Gambús PL, Jensen EW, Jospin M, Borrat X, Martínez Pallí G, FernándezCandil J, et al. Modeling the effect of propofol and remifentanil combinations for sedation-analgesia in endoscopic procedures using an adaptive neuro fuzzy inference system (ANFIS). Anesth Analg. 2011;112(2): 331-9. https://doi.org/10.1213/ANE.0b013e3182025a70.

44. Chakravarthy $M$, Holla S, Jawali V. Index of consciousness and bispectral index values are interchangeable during normotension and hypotension but not during non pulsatile flow state during cardiac surgical procedures: a prospective study. J Clin Monit Comput. 2010;24(2):83-91. https://doi.org/10. 1007/s10877-009-9214-8

45. Kreuzer M, Zanner R, Pilge S, Paprotny S, Kochs EF, Schneider G. Time delay of monitors of the hypnotic component of anesthesia: analysis of state entropy and index of consciousness. Anesth Analg. 2012;115(2):315-9. https://doi.org/10.1213/ANE.0b013e31825801ea.

\section{Ready to submit your research? Choose BMC and benefit from:}

- fast, convenient online submission

- thorough peer review by experienced researchers in your field

- rapid publication on acceptance

- support for research data, including large and complex data types

- gold Open Access which fosters wider collaboration and increased citations

- maximum visibility for your research: over $100 \mathrm{M}$ website views per year

At BMC, research is always in progress.

Learn more biomedcentral.com/submissions 